\title{
An Expert System Oriented towards the Detection of Influenza and Dengue Developed on Mobile Platforms
}

\author{
Raúl Beltrán Ramírez¹, Rocío Maciel Arellano', Carlos González Sandoval², \\ Adauto Casas Flores ${ }^{1}$ \\ ${ }^{1}$ Departamento de Sistemas de Información, Universidad de Guadalajara Periférico Norte, Zapopan, México \\ ${ }^{2}$ Centro de Enseñanza Técnica Industrial, Guadalajara, México \\ Email: jrbeltran@cucea.udg.mx, rmaciel@cucea.udg.mx, carlos.augusto.gs@hotmail.com, \\ adauto.casas@gmail.com
}

Received 7 May 2015; accepted 14 June 2015; published 17 June 2015

Copyright (C) 2015 by authors and Scientific Research Publishing Inc.

This work is licensed under the Creative Commons Attribution International License (CC BY). http://creativecommons.org/licenses/by/4.0/

(c) (i) Open Access

\begin{abstract}
Nowadays, mobile technology makes it possible for us to realize processes in a relatively short amount of time, showing the user friendly and efficient interfaces that any person is capable of adapting to. Continuing this trend, we develop a mobile application that aids in giving an early diagnosis of Influenza and Dengue, two diseases that affect approximately $5 \%$ of the world population (in the case of Dengue) and 5\% - 15\% of the northern hemisphere (in the case of influenza). Our application consists of an expert system based on fuzzy logic that analyzes symptoms introduced by the user and formulates a diagnosis in approximately 2 - 4 minutes. This system considerably reduced the diagnostic time, improving the recuperation process from these diseases due to their early detection.
\end{abstract}

\section{Keywords}

Mobile Technology, Mobile Applications, Dengue, Influenza, Expert System

\section{Introduction}

In Mexico, two of the diseases that have most caused health problems in the society are Dengue and Influenza H1N1, whose symptoms can be confused amongst themselves or other simple sicknesses which in many cases can lead to a late diagnosis.

Influenza is an acute, contagious viral respiratory disease whose typical manifestations are fever, myalgia, 
coryza, throat pains and coughing. The influenza virus usually attacks the superior respiratory tract. However, in more extreme cases, it can affect the lower respiratory tract (lungs and bronchioles) [1]. In the past 100 years, there have been 4 pandemics: one in 1918 caused by the Influenza Virus A (H1N1), in 1957 by the type A (H2N2), in 1968 by A (H3N2), and in 2009 A (H1N1). The last pandemic led to a severe health problem due to the similitude of its symptoms with those of a common cold [2] [3].

The epidemiological vigilance is the key to an early detection of the first cases of this disease, helping the patient increase their recovery expectations and simultaneously fire an alarm and start response actions to avoid another pandemic [4].

Dengue disease is the most prevalent arthropod-borne viral disease in humans. It is caused by four serotypes of single-strand RNA flavivirus (dengue virus [DENV]-1, -2, -3, and -4), which are transmitted by blood-feeding mosquitos - mainly Aedesaegypti (Linnaeus) [5] [6].

It's one of the most important re-emerging diseases in the world [7]. There are between 50 - 100 million cases annually in over 100 countries and in the majority of those cases it is manifested as flu syndrome and causes approximately 24,000 deaths per year. Around $2.5 \%$ of the infected cases result to be fatal due to lack of adequate treatment. Access to capacitated professionals or intelligent systems that recognize symptoms for a rapid diagnosis is of utmost importance [8].

In the present day, the rapid development of technology and telecommunications has offered humanity the opportunity to improve areas such as education, industrial productivity and productivity in general for that matter, and of course video game development, pressuring technological evolution worldwide. Some examples of the implementation of this technology can be observed in applications that carry out image analysis and threedimensional reconstruction utilizing specific information. These diagnoses would have been impossible without the aid of experts. However once developed, this project would be useful in places where mentioned experts would not be of disposition, for example, accidents where muscular or bone damage is present.

In this case, our developed application (BioDnX) is focused on the diagnosis of diseases such as Influenza and Dengue, which have taken many lives on a global scale every year. Commonly, when people suffer of the first symptoms, they wait 1 to 3 days before consulting a physician and as more time goes by, the probabilities of recover are slimmer. BioDnX directly impacts this aspect, reducing the diagnostic time for all people with access to mobile platforms, enabling better recovery times, treatment and possibly saving the patient's life. Apart from the simple and friendly environment, the available assistant (Dr. DnX), in every stage of the application, converts someone of any age into a potential user without presenting any difficulty in its use or operation.

\section{Material and Methods}

Many electronic devices have been employed, such as a personal computer capable of running the developing software “Adobe Flash CS6”, a mobile device "Smart Phone” (Motorola G2) for testing and many others such as tablets, iPads and other Android operating system devices.

\subsection{Hardware}

Computer: CPU: Intel Core i5-3210M 2.5 GHz, RAM: 6 GB, OS: Windows 8.1 Single Language 64 bits.

Testing Devices: Android Operating System Lg L5x, Moto G2 and Samsung Galaxy S3 mini.

\subsection{Software}

Adobe Flash Professional CS6, Animation Software for app development, Adobe Air Version 15.00.249 (programming language converter for iOS and Android Systems), Adobe Photoshop CS6 Version 13.0 (photo and image editor), CorelDraw Graphics Suite X6 64bits Version 16.0.707 (image designer).

\subsection{Fuzzy Logic}

Fuzzy logic is an alternative logic as opposed to classical logic which introduces a level of uncertainty in what it evaluates, in the world that we live in there exists many ambiguous or imprecise concepts of nature. Fuzzy logic was designed precisely to imitate human behavior.

A diagnostic can be obtained due to the evaluation of the symptoms implementing fuzzy logic, we cannot de- 
termine exactly when a patient is actually suffering of these diseases or not, however we can calculate the probability of the user being victim to these diseases.

The program calculates every symptom, paying close attention to the slightest of details, (this is where expert knowledge comes into play), the user selects the symptoms presented and the system calculates the probability of the user possessing each disease. Finally, the diagnosis is determined based on the inputted symptoms.

\subsection{Differentiation of Diseases}

The similitude between the symptoms of these two diseases is quite high, thus there is a probability of confusion between the two diseases upon their diagnosis, to resolve this confusion the system proceeds to ask the user if he/she has certain symptoms that they might have overlooked upon inputting data in the main menu, helping the system calculate the probabilities of their diagnosis as accurately as possible.

\section{Project Development}

An expert system which implements fuzzy logic to give an approximate diagnosis of Influenza and Dengue utilizing a friendly interface based on images, where the user selects his/her gender and parts of the body where he/she feels pain with a simple tap, taking into consideration the patient's age as the first parameter.

After inputting all of the user's symptoms, the consultation is finalized by tapping the "OK" button from the main menu. The system also contains an assistant, Dr. DnX that makes the user experience much more comfortable.

In order to proceed with the development process and to create a knowledge database that contains all the symptoms and their values, it was necessary to consult information from medical experts in the Virology area at the University of Guadalajara.

\subsection{Knowledge Database}

Table 1 shows us the database created during the investigation process, completed from the expert knowledge in virology from the University of Guadalajara. We investigated the symptoms presented in both diseases and assigned a numeric value based on the impact caused by each disease. The assigned values were corroborated and accepted by the earlier mentioned medical experts.

\subsection{Operations}

Equation (1) and Equation (2), describe each disease operation, adding each value of the symptoms corresponding to index (i).

$$
\begin{gathered}
\sum_{i=0}^{i=10} \text { Influenza }=\text { Influenza }+ \text { Symptom }[\mathrm{i}] \\
\sum_{i=8}^{i=20} \text { Dengue }=\text { Dengue }+ \text { Symptom }[\mathrm{i}]
\end{gathered}
$$

At the final stage of the application in the diagnosis window, the algorithm compares the values of both disease variables and shows the higher result to the user.

\section{Research Procedure}

In Figure 1 our algorithm is represented by a flow diagram to analyze the information from each user's diagnosis. This procedure simulates the behavior of a medical consultation, taking into account symptoms, their relation, and differentiating between Influenza and Dengue. If the quantity of Dengue symptoms is equivalent to that of Influenza symptoms, the system reminds the users of symptoms that they may not have inputted at the beginning of the simulated consultation to correctly diagnose said user.

\section{Experiment Results}

In this development we implemented mobile technology to improve the pre-diagnostic times in case of the need for efficient and accurate recognition of the symptoms pertaining to said diseases. The development of BioDnX 
Table 1. Knowledge database (information obtained by medical experts).

\begin{tabular}{|c|c|c|c|c|}
\hline \multirow{2}{*}{ Disease } & \multicolumn{4}{|c|}{ Symptoms and values } \\
\hline & Symptom & Index & Value & Impact \\
\hline Influenza & Nasal irritation & 0 & 8 & High \\
\hline Influenza & Loss of appetite & 1 & 5 & Moderate \\
\hline Influenza & Red eyes & 2 & 10 & High \\
\hline Influenza & Watery eyes & 3 & 7 & High \\
\hline Influenza & Cough & 4 & 5 & Moderate \\
\hline Influenza & Nasal congestion & 5 & 7 & High \\
\hline Influenza & Breathing difficulties & 6 & 3 & Low \\
\hline Influenza & Sore throat & 7 & 15 & High \\
\hline Influenza/dengue & Fever (temperature $>99^{\circ} \mathrm{F}$ ) & 8 & 40 & High \\
\hline Influenza/dengue & High temperature to touch & 9 & 20 & High \\
\hline Influenza/dengue & Diarrhea & 10 & 2 & Low \\
\hline Dengue & Vomit & 11 & 1 & Low \\
\hline Dengue & Drowsiness & 12 & 8 & High \\
\hline Dengue & Joint-aches & 13 & 7 & High \\
\hline Dengue & Skin Problems & 14 & 6 & Moderate \\
\hline Dengue & Headaches & 15 & 7 & Moderate \\
\hline Dengue & Eye-aches & 16 & 6 & High \\
\hline Dengue & Chills & 17 & 3 & Low \\
\hline Dengue & Chest pressure & 18 & 2 & Low \\
\hline Dengue & Body pain & 19 & 15 & High \\
\hline Dengue & Dizziness & 20 & 3 & Low \\
\hline
\end{tabular}

${ }^{\mathrm{a}}$ Knowledge database implemented on BioDnX (supervised by medical experts).

showed satisfactory results regarding the detection time of these two diseases, due to what granted the patients a pre-diagnosis within 2 - 4 minutes. It is common for people with the first symptoms to wait days while scheduling a physician's appointment before being able to receive a reliable diagnosis. BioDnX considerably reduced the time of uncertainty concerning these diseases by allowing the patients to have access to a tool permitting reliable diagnoses.

Table 2 shows us the duration of the disease and the diagnosis time. Data of the evolution of the disease was collected from different people at different times to recognize the early symptoms which are generally presented, when the patient was first diagnosed with the disease, its progress and his/her recovery time. These same people were offered to try BioDnX, simulating the same early symptoms, and the pre-diagnosis showed results after approximately 2 - 4 minutes.

\section{Application's Environment}

Figure 2 and Figure 3, show the appearance of the system and the environment that the user will experience. We utilized a Motorola G2 cellular device and the testing was done with the Android KitKat 4.4 operating system. 


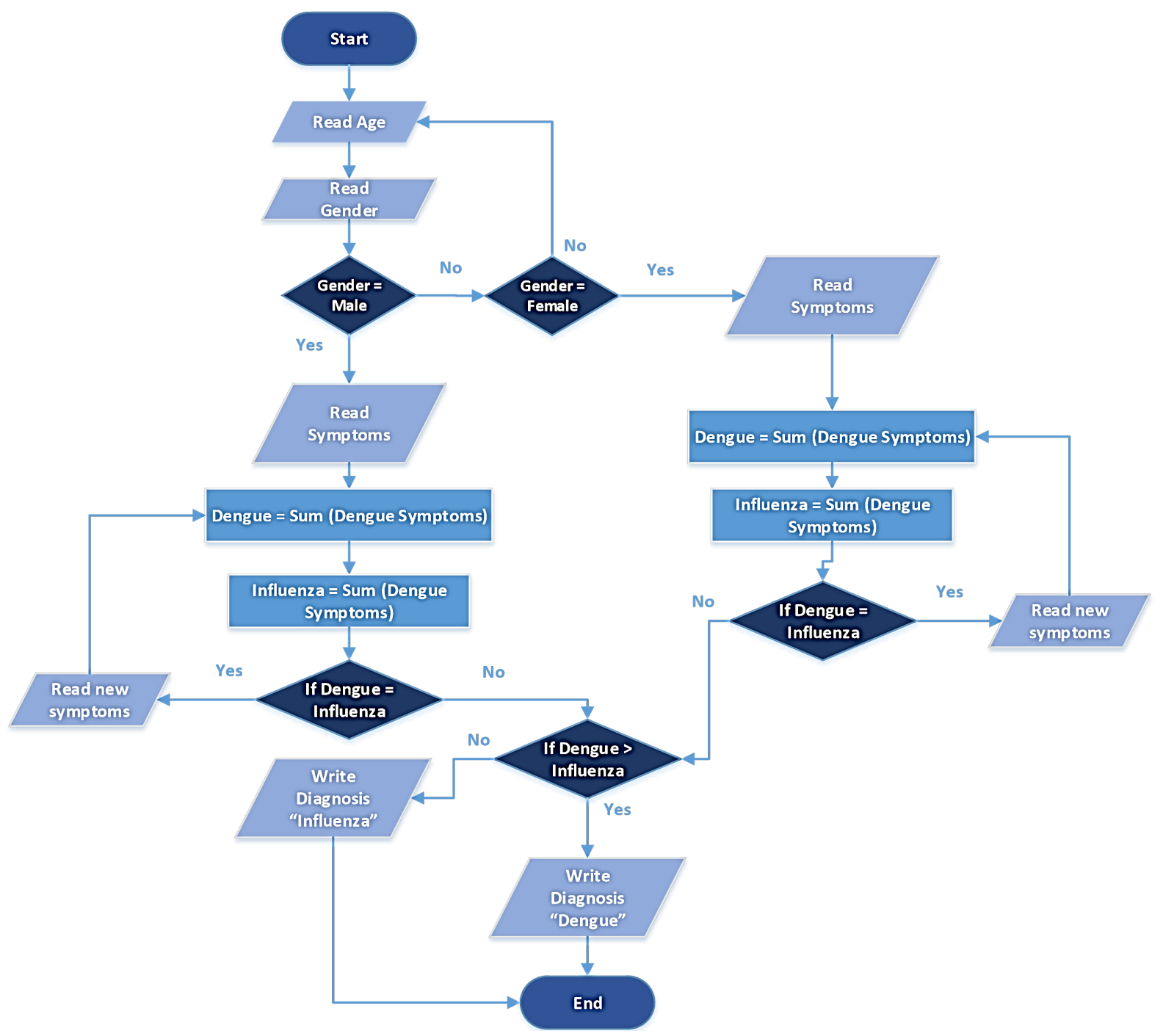

Figure 1. BioDnX flowchart (shows every step of the diagnosis process).

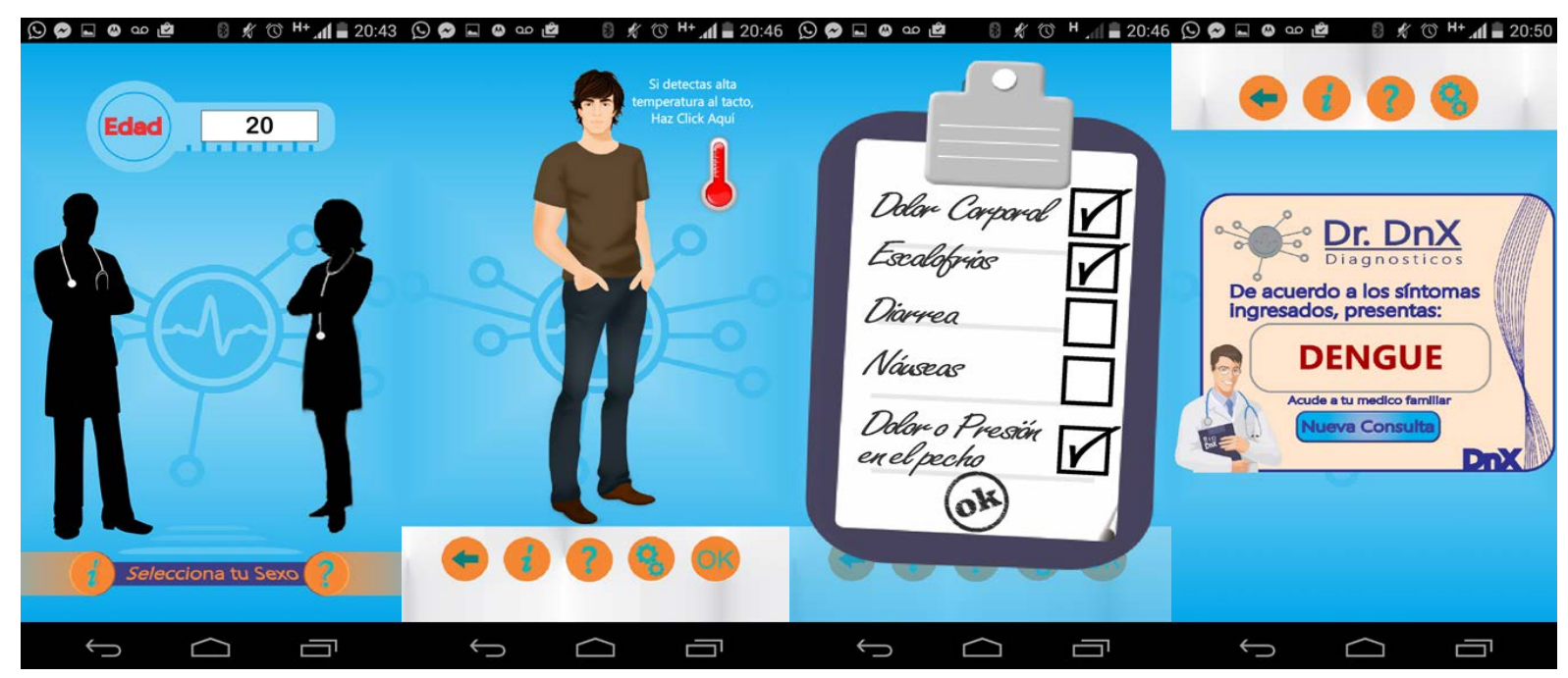

Figure 2. BioDnX environment (designed for easy, quick and accurate use). 

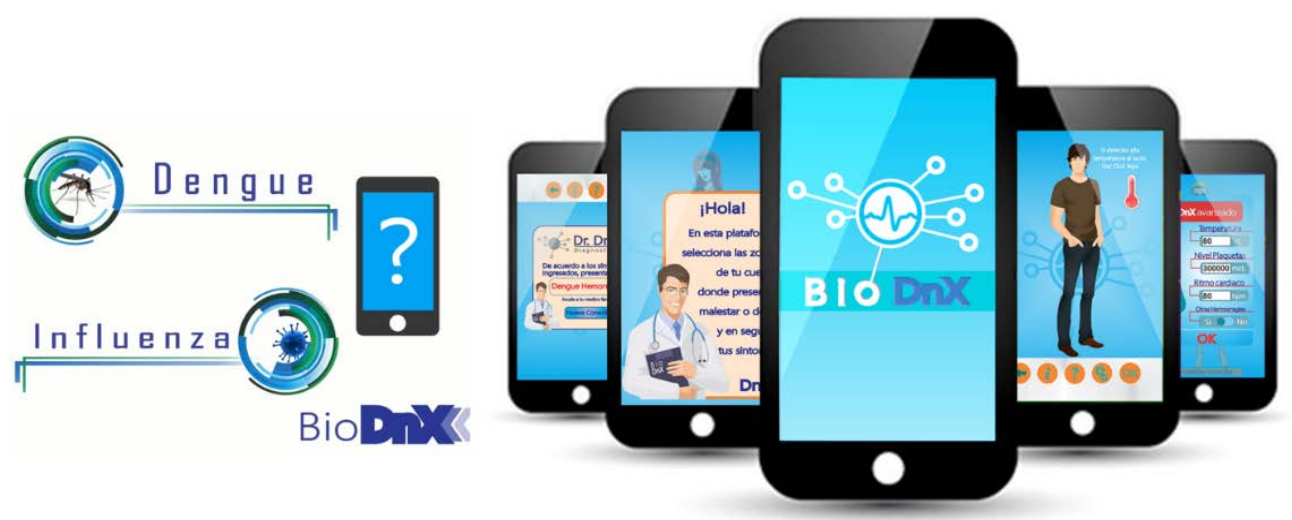

Figure 3. BioDnX fully functional (available only on android mobile devices).

Table 2. Experiment results (with real and simulated cases).

\begin{tabular}{|c|c|c|c|c|c|}
\hline \multirow{2}{*}{ Situation } & \multicolumn{5}{|c|}{ Diagnosis data } \\
\hline & Name & Diagnosis & $1^{\text {st }}$ symptom date & Diagnosis date & Recovery time \\
\hline Without BioDnx & $\begin{array}{l}\text { Marisela Fernandez } \\
\text { Serrano }\end{array}$ & Dengue & $\begin{array}{l}27 / 04 / 2010 \\
\text { Body pain }\end{array}$ & 29/04/2010 & 12 days \\
\hline With BioDnx & & $\begin{array}{l}\text { High probabilities } \\
\text { of dengue }\end{array}$ & $\begin{array}{l}14 / 05 / 2015 \\
5: 07 \mathrm{pm}\end{array}$ & $\begin{array}{l}14 / 05 / 2015 \\
5: 09 \mathrm{pm}\end{array}$ & - \\
\hline Without BioDnx & $\begin{array}{l}\text { Nicole Muñoz } \\
\text { Filippetti }\end{array}$ & Dengue & $\begin{array}{l}\text { 09/10/2012 } \\
\text { Joints-aches }\end{array}$ & $12 / 10 / 2012$ & 15 days \\
\hline With BioDnx & & Dengue & $\begin{array}{l}14 / 05 / 2015 \\
11: 18 \mathrm{pm}\end{array}$ & $\begin{array}{c}14 / 05 / 2015 \\
11: 21 \mathrm{pm}\end{array}$ & - \\
\hline Without BioDnx & $\begin{array}{l}\text { Carlos Gonzalez } \\
\text { Ávila }\end{array}$ & Dengue & $\begin{array}{l}\text { 20/08/1998 } \\
\text { Eye-aches }\end{array}$ & 24/08/1998 & 11 days \\
\hline With BioDnx & & $\begin{array}{l}\text { High probabilities } \\
\text { of dengue }\end{array}$ & $\begin{array}{l}15 / 05 / 2015 \\
12: 09 \mathrm{am}\end{array}$ & $\begin{array}{l}15 / 05 / 2015 \\
12: 12 \mathrm{am}\end{array}$ & - \\
\hline Without BioDnx & $\begin{array}{l}\text { Fernando Miguel } \\
\text { Saucedo }\end{array}$ & Influenza & $\begin{array}{c}\text { 02/03/2013 } \\
\text { 10:00 am } \\
\text { Simple Flu }\end{array}$ & $\begin{array}{l}02 / 03 / 2013 \\
8: 00 \mathrm{pm}\end{array}$ & 3 days \\
\hline With BioDnx & & $\begin{array}{l}\text { High probabilities } \\
\text { of influenza }\end{array}$ & $\begin{array}{l}15 / 05 / 2015 \\
12: 55 \mathrm{am}\end{array}$ & $\begin{array}{c}15 / 05 / 2015 \\
12: 57 \mathrm{am}\end{array}$ & - \\
\hline Without BioDnx & $\begin{array}{c}\text { Jonathan Arredondo } \\
\text { Macias }\end{array}$ & Dengue & $\begin{array}{l}\text { 27/05/2009 } \\
\text { Fever }\end{array}$ & 4/06/2009 & 21 days \\
\hline With BioDnx & & Dengue & $\begin{array}{c}15 / 05 / 2015 \\
1: 08 \mathrm{am}\end{array}$ & $\begin{array}{c}15 / 05 / 2015 \\
1: 11 \mathrm{am}\end{array}$ & - \\
\hline
\end{tabular}

${ }^{\mathrm{a}} \mathrm{BioDnX}$ was used for the recreation of the cases (the procedure was executed with the same symptoms presented on the same day).

\section{Discussion}

In this investigation we designed an Android based application utilizing human expertise to obtain an early diagnosis of Influenza and Dengue, whose symptoms are very similar, taking into account the growing use of mobile devices in the Mexican population. Given that both diseases have impacted the population and due to the time consuming diagnoses, many lives have been lost. We hope that with an application of this nature, the society can have a tool to obtain information pertaining to their symptoms in a timely manner.

We utilized BioDnX to improve the response time of the diagnosis of diseases Influenza H1N1 and Dengue and even though this is just a pre-diagnosis, this will aid the physician. However, it is necessary to debug the diagnostic algorithm to add more diseases and symptoms to the database. 


\section{References}

[1] Neumann, G. and Kawaoka, Y. (2015) Transmission of Influenza A Viruses. Virology, 479-480, 234-246. http://www.sciencedirect.com/science/article/pii/S0042682215001452 http://dx.doi.org/10.1016/j.virol.2015.03.009

[2] Scalera, N.M. and Mossad, S.B. (2009) The First Pandemic of the 21st Century: A Review of the 2009 Pandemic Variant Influenza A (H1N1) Virus. Postgraduate Medicine, 121, 43-47. http://dx.doi.org/10.3810/pgm.2009.09.2051

[3] Centers for Disease Control and Prevention (CDC) (2011) Self-Reported Influenza-Like Illness during the 2009 H1N1 Influenza Pandemic-United States, September 2009-March 2010. Morbidity and Mortality Weekly Report, 60, 37.

[4] Nucamendi Cervantes, G. (2014) Epidemiología de Influenza en México. Subsecretaría de Prevención y Promoción de la Salud, 32-36.

[5] Gomez-Dantés, H., et al. (2011) La estrategia para la prevención y el control integrado del dengue en Mesoamérica. Saludpública Méx, 53, s349-s357.

[6] Gubler, D.J., Ooi, E.E., Vasudevan, S. and Farrar, J. (2014) Dengue and Dengue Hemorrhagic Fever. CABI.

[7] Fajardo-Dolci, G., Meljem-Moctezuma, J., Vicente-González, E., Venegas-Páez, F.V., Mazón-González, B. and AguirreGas, H.G. (2012) Dengue Fever in Mexico. Knowledge for Improving the Quality of Health. Revista Médica del Instituto Mexicano del Seguro Social, 50, 631-639.

[8] Guzman, M.G. and Harris, E. (2015) Dengue. The Lancet, 385, 453-465.

http://www.sciencedirect.com/science/article/pii/S0140673614605729 http://dx.doi.org/10.1016/S0140-6736(14)60572-9 